\title{
Genesis and Evolution of the Agile Movement in Brazil - A perspective from the Academia and the Industry
}

\author{
Hugo Corbucci, Alfredo Goldman, Eduardo Katayama, \\ Fabio Kon, Claudia Melo and Viviane Santos \\ Department of Computer Science \\ Institute of Mathematics and Statistics \\ University of São Paulo, Brazil \\ \{corbucci, gold, eduardo, fabio.kon, claudia, vsantos\}@ime.usp.br
}

\begin{abstract}
Agile Software Development methods have been increasingly adopted worldwide and became one of the mainstream software development approaches. Agile methods have also had an impact on software engineering education with universities adapting their courses to accommodate this new point of view of software development. Software engineering research has tried to evaluate the impact of agile methods in industrial projects and discover in which situations it is beneficial to apply such methods. However, there are still few studies focusing on the progress of the Agile movement in Brazil.

In this paper, we present an overview of the evolution of the Agile movement in Brazil, outlining the history of its first advocates in academia and industry. We also describe existing educational initiatives and the impact of Agile on the national research and present a report on the agile state-of-the-practice in the Brazilian IT industry.
\end{abstract}

\section{INTRODUCTION}

The birth of the Agile movement around the year 2000 was a consequence of a variety of factors, ideas, and proposed best practices that arose, mainly, in the context of ObjectOriented (OO) Programming. These ideas echoed previous works such as The Mythical Man-Month: Essays on Software Engineering by Frederick P. Brooks [Bro75] and the concept of Rapid Prototyping [NJ82]. Multiple research and practitioner groups gathered in larger communities, such as the one around the ACM International Conference on Object-Oriented Programming, Systems, Languages, and Applications (OOPSLA), produced ideas that led to the development of the concept of Agile Software Development.

The role of the Smalltalk programming language community was also fundamental. Three important points from that community led to changes. The first was its minimal syntax that let programmers write code that looked like natural language sentences. The second its dynamic typing that provided high flexibility. Lastly a powerful programming environment centered around its dynamic and flexible class browser that influenced modern IDEs. Through those aspects, Smalltalk fostered the development of the technology and the spirit that enabled a different way of developing software.

In the second half of the 1990s, research and practical results in the fields of $\mathrm{OO}$, design patterns, automated testing, refactoring, and the like, produced a common mind set that drove the definition of multiple software development methods that had the core agile principles in common. These methods include Extreme Programming (XP), SCRUM, DSDM, Adaptive Software Development, Crystal, Feature-Driven Development, Pragmatic Programming, and others.

In early 2001, a group of independent practitioners with a strong link with the software industry and a, weaker but still relevant, link with research groups from academia decided to join forces and founded what was later called the Agile movement. To make these ideas more concrete, 17 software experts met from February 11th to 13th in the mountains of Utah, USA to collectively craft the Agile Manifesto ${ }^{1}$. The goal of the manifesto was to bring attention to the idea that, to produce high-quality, valuable software, development teams must focus on (1) Individuals and interactions, (2) Working software, (3) Customer collaboration, and (4) Responding to change. Those points were presented as more important than emphasizing processes and tools, comprehensive documentation, contract negotiation, and following previously-defined plans.

\section{The Genesis}

Pioneering agile methods and the agile movement itself became known worldwide in 1999, the year in which Kent Beck's XP book [Bec99] was published and released during the ACM OOPSLA conference in Denver, Colorado. In 2000, the 1st International Conference on eXtreme Programming and Agile Processes in Software Engineering (XP'2000) took place in Sardinia, Italy. At this time, a few Brazilian software developers from academia and industry got in touch with the movement. Klaus Wuestefeld, a software developer working in the Brazilian software industry attended XP'2000 and met key figures from the movement, such as Kent Beck, Alistair Cockburn, Martin Fowler, Ron Jeffries, and Robert Martin (a.k.a., Uncle Bob). Fabio Kon was at OOPSLA in 1999 and 2000, attended Beck's talks and got involved with the big frisson that XP and agile methods made during those

\footnotetext{
${ }^{1}$ www.agilemanifesto.org
} 
conferences. Immediately after the 1999 event, he came back to the University of Illinois at Urbana-Champain, where he was a post-doctoral research associate, and started to apply extreme programming practices and give talks about Beck's new book.

Kon came back to Brazil in January, 2001, and soon gave a talk about Extreme Programming at the Department of Computer Science at IME, University of São Paulo. After a few months, with Prof. Alfredo Goldman and Prof. Carlos Eduardo Ferreira, they decided to experiment with a fullsemester course on Extreme Programming in which students would develop real software projects using all the XP practices rigorously. This Extreme Programming Laboratory elective course (see http://www.ime.usp.br/ xp) became popular with the students rapidly. After 10 years, in 2011, nearly 300 students attended the course and questionnaires filled out by participants show that the course is very well evaluated by students, who often mention it to be the best course in their curriculum. Most of these students, go out to work in the software industry shortly after the course, and often start to disseminate agile methods in their organizations. Several course alumni such as Alexandre Freire, Dairton Bassi Filho, and Danilo Sato, started to act as consultants and project leaders and helped to introduce agile methods in software development companies.

In the years after 2001, Wuestefeld, Kon, Goldman, and Teles gave several lectures and short courses on Extreme Programming and Agile Methods to the Brazilian academic and industrial communities. This was fundamental in disseminating the practical use of these methods in real software development projects in Brazil.

By that time, in the industry, Wuestefeld was organizing "Extreme Programming Brasil 2002", which marked the first agile event in Brazil as well as Kent Beck's first and only visit to the country. It was held in São Paulo during 3 days at the beginning of December and had Scott Ambler and Rob Mee along with Kent Beck as international guests. Kon and Goldman presented their experience with the course on XP at the University of São Paulo, while Vinicius Teles presented his experience on a similar initiative at the Federal University of Rio de Janeiro. A couple of years later, Wuestefeld managed to put together "Extreme Programming Brasil 2004" and brought Mary and Tom Poppendieck with the support of several companies. Agile methods were starting to gain strenght both in the academia and in the industry.

\section{Agile Methods Education}

There were several initiatives on promoting agile methods in Brazil within the Academy. The oldest and still running one is probably the course Extreme Programing Laboratory at IME-USP ${ }^{2}$. It occurs once an year, during a full semester for Computer Science undergraduate and graduate students. The first edition was in 2001 when three professors gave the course for a dozen students. Since then, the course has evolved

\footnotetext{
${ }^{2}$ http://www.ime.usp.br/ $\sim$ xp/projects.php
}

and scaled up to eight concurrent projects and teams and over fifty students. To support such growth, former students were encouraged to assume a coaching role in the following editions. This way, the lab replicated a meritocracy system similar to the industry and allowed some very experienced students to assume teaching assistant roles and work as metacoaches during the courses. As meta-coaches, the experienced students were supposed to serve as gurus for all groups providing feedback, supervising the practices and helping with the adoption of new practices.

To set up a closer to real environment, the XP customers are chosen among several university demands or open source projects. All the systems developed are available as free software. The course starts with three weeks of theoretical classes, when the basics of Agile Methods and XP are introduced; then, the students can choose the projects they are willing to work on. Usually, each project gets from four to eight participants; if there is no experienced student on the group, a coach is elected among the volunteers. The groups without an experienced coach receive more attention from the metacoaches. A tracker or group of trackers is also elected. The initial practices adopted on the start of the projects are the 12 from the first edition of XP's book; in addition, daily stand-up meetings and informative workspaces are also used. All teams have to carry out retrospectives at the end of each iteration. To grade the students, an average of grades for attendance, pro-active participation, tracking, customer satisfaction, and personal, coach, and meta-coach evaluation is calculated.

Using this course as a testbed, several scientific publications were produced, addressing multiple topics, from working software such as Archimedes [CB07], Mezuro $\left[\mathrm{MSM}^{+} 10\right]$, $\left[\mathrm{TCM}^{+} 10\right]$ and Mico $\left[\mathrm{SAK}^{+} 04\right]$ to experiments on teaching XP [GKSY04] or XP related techniques [BG10]. Two recent papers on tracking [OG11] and organizational learning [SGSF11] also used the XP lab environment.

With the success of the first editions of IME-USP XP laboratory, a presentation on its concept was given in the Brazilian Quality Symposium in 2002, a forum where the good teaching ideas and techniques are spread among different Universities, during the annual congress of the Brazilian Computer Society (SBC).

A similar initiative on teaching XP was lead by Vinícius Teles at UFRJ, starting in the second semester of 2002. The approach used by Teles was different; there were two parts on each lecture: first a theoretical one in which the students had to answer questions orally based on the material provided earlier. For the practical part, instead of having a project for each team during the whole course, several short exercises on each practice were proposed. The motivation was to reinforce the learning of each practice, always practicing pair programming. At each day, the pairs were randomly chosen. The grades were mainly given based on the attendance and on the answers.

On the industry side, we can cite the example of Caelum, a Brazilian company with business on both training and software development. They have several short courses on Java and object-oriented techniques. They started a course on Scrum 
on 2006, and two months latter a course on XP. However, the XP course was shortly discontinued since there was not enough industrial interest at that time. Recently, Caelum started to offer two new courses, one on Lean, through a Lean Lego Game, and the other on agile practices for software development heavily based on XP, which includes unit and acceptance tests, test driven development, and refactoring.

In 2006, as agile methods started to explode, some professors and students at IME-USP decided to offer a summer course to promote those ideas beyond the limits of the university. It was a 20 hours theoretical course spread along 5 days with 2 instructors each day. The result was a success and all teaching material was published at the Agilcoop website ${ }^{3}$ to be used freely. The following three years continued to offer the course and added different courses such an eXtreme Programming Laboratory to offer a more practical approach and a testing course to study more deeply that subject. During this time, over 200 people attended the theoretical course, over 60 attended the practical course and around 50 were on the testing course.

Another important player in the agile methods growth was the method known as Scrum [SB01]. Although it has its origins earlier than XP, it only became very widely known around 2006 when Scrum Alliance ${ }^{4}$ (a non-profitable organization) became a corporate entity and started a certification process to gather professionals which attended their criteria. The alliance offers several certification stamps which can only be given by certified trainers. Until August 2008, all certifications given in Brazil were offered by foreign trainers in English. That date marks the first Brazilian Certified Scrum Trainer (CST), Alexandre Magno. The certification fulfilled an important hole to the industry as it presented a way to "prove" the knowledge of companies regarding agile methods. Since then, two other Brazilians obtained the CST certificate (Heitor Roriz and Michel Goldenberg) and the demand for certified scrum courses never stopped growing. Recently, a discussion regarding the certification led to the creation another foundation (Scrum.org ${ }^{5}$ ) separating Ken Schwaber (Scrum.org) and Jeff Sutherland (Scrum Alliance) and provoking a rupture in the Scrum community. Giovanni Bassi was the first Brazilian to obtain the Professional Scrum Master Trainer (PSMT) and the Professional Scrum Developer Trainer (PSDT) certifications. Soon, two more Brazilians (Felipe Rodrigues de Almeida and Victor Hugo de Oliveira) obtained the Professional Scrum Developer Trainer certificate. This new scenario will certainly impact the Scrum community but the fact that certification systems is a success on the industry is undeniable and many people got in touch with agile through these certification programs.

Another initiative to foster the adoption of Agile Methods was done in the several editions of the Encontro Ágil workshop ${ }^{6}$. On the first editions, the main focus was on

\footnotetext{
${ }^{3} \mathrm{http} / / / \mathrm{ccsl}$.ime.usp.br/agilcoop/curso_de_verao_2007

${ }^{4} \mathrm{http}: / /$ www.scrumalliance.org

${ }^{5}$ http://www.scrum.org

${ }^{6} \mathrm{http}: / /$ www.encontroagil.com.br
}

tutorials and panels to teach or provide working evidences on Agile Methods and related techniques. To provide interesting information for a broad audience, the workshops were divided in three main categories, Keynote talks usually with an invited speaker, advances tracks and introductory tracks. However, in the last edition in 2010, there was a major change, instead of providing talks, only workshops with more interactive possibilities were present. There was also a larger emphasis on Open Spaces and Lightning Talks.

Finally, in 2003, a tutorial on Agile Methods and XP was presented at SBES in 2003. This was the predecesor for a new tutorial that will be held at SBES on 2011 about Agile Methods. The new tutorial's main motivation is to show the current challenges and present evidences on Agile Methods effectiveness.

\section{Agile Methods Research}

To the best of our knowledge, the first review of Brazilian academic papers on Agile Software Development was published by our group in the Brazilian Workshop on Agile Methods (WBMA'2011) [GK11], this section extends those results.

The first part of the study consisted in identifying researchers working with fields related to Agile Methods. The search strategy for researchers included a list of contacts and hand searches of national conferences proceedings such as $\mathrm{WBMA}^{7}, \mathrm{ESELAW}^{8}$ and $\mathrm{WDRA}^{9}$, and international conferences such as Agile ${ }^{10}$ and $\mathrm{XP}^{11}$. We identified 36 researchers on Agile Software Development. From 1997 to 2011, they advised 23 MSc and PhD students. As we can see in Table I, there seems to be a substantial increase in interest of graduated students on the topic of Agile Methods.

TABLE I

ALUMNI AND CURRENT MSC AND PHD STUdENTS

\begin{tabular}{|c|c||c|c|}
\hline \multicolumn{2}{|c||}{ Former Students } & \multicolumn{2}{c|}{ Current Students } \\
\hline MSc & PhD & MSc & PhD \\
\hline 23 & 0 & 14 & 4 \\
\hline
\end{tabular}

With respect to the kinds of agile methods that have been studied by the graduated students, we see that most of the studies identified were on agility in general (12 of 23). Studies on XP come next, with seven works. Most studies were conducted in a university setting, and were of short duration (6 months), and completed in small teams - up to seven team members. Four themes frequently recurred across studies: (1) How agile development methods are introduced and adopted in companies, (2) Comparison of agile development against

\footnotetext{
${ }^{7}$ Workshop Brasileiro de Métodos Ágeis - www.agilebrazil.com/2011/pt/ wbma.php

${ }^{8}$ Experimental Software Engineering Latin American Workshop - http:// cibse.inf.puc-rio.br/pt/program_eselaw.php

${ }^{9}$ Workshop de Desenvolvimento Rápido de Aplicações - http://promise.cin. ufpe.br/wdra2011/index.html

${ }^{10}$ Agile Conference Series - http://agile2011.agilealliance.org/

${ }^{11}$ The last edition of the conference - http://xp2011.org/
} 
an alternative, (3) Human and social factors related to agile development, and (4) Investigation of specific agile practices.

To describe the status of Brazilian research on Agile Software Development, for each researcher identified, we conducted a literature search in the Lattes Database ${ }^{12}$. This search strategy resulted in a total of 2239 unduplicated papers published between 1997 and 2011. During the literature review stage, we noticed that most of these publications were unrelated to the topic on which our research was focused. Since the number of publications were high, we identified the more relevant, as explained below, and concentrated our review on them. A large number of the publications were excluded when not directly related to agile software development.

Figure 1 shows the review process and the number of papers identified at each stage. In stage 1, all publications from the researchers identified were selected. We first excluded from the initial set, works related to panels, summaries of tutorials, news, and magazines. At stage 2, we went through the titles of all studies that resulted from stage 1 , to determine their relevance. At this stage, we excluded 2072 studies that were clearly not related to agile software development. In stage 3 , we excluded the study if it was unclear from the title, abstract, and keywords whether it were related to agile, which left 105 publications. Among them, 92 were papers in conference proceedings (88\%) and 13 were journal articles (12\%).

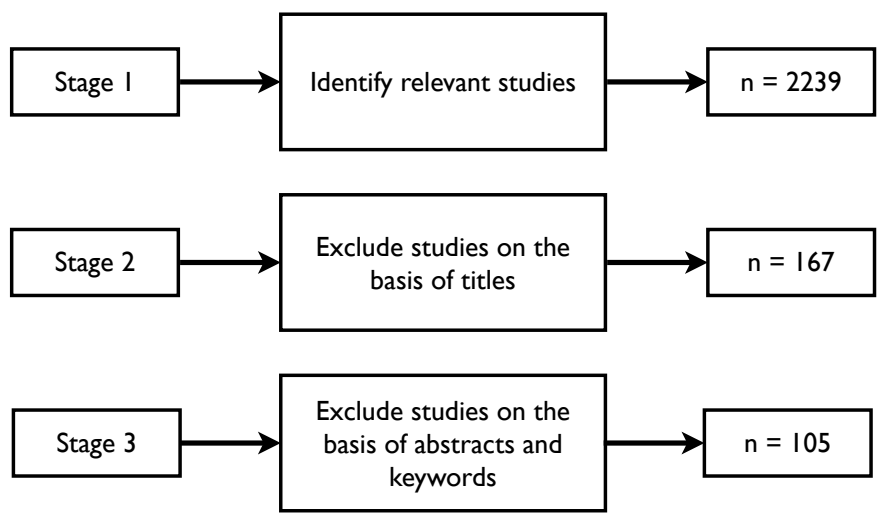

Fig. 1. Stages of the selection process

An examination of the state of origin of the publications shows that most studies are from São Paulo and Pernambuco. The University of São Paulo has the highest number of publications, followed by the Federal University of Pernambuco. Figure 2 present the institutions that are more frequently occurring in the search and their relationships. The productions with equal or similar title (within the same type and year of publication) are considered to be collaborations among researchers.

\section{A. Current Research on Agile Software Development}

To describe the status of current research on Agile Software Development in Brazil, we conducted a literature search in

\footnotetext{
${ }^{12} \mathrm{http}: / /$ lattes.cnpq.br
}

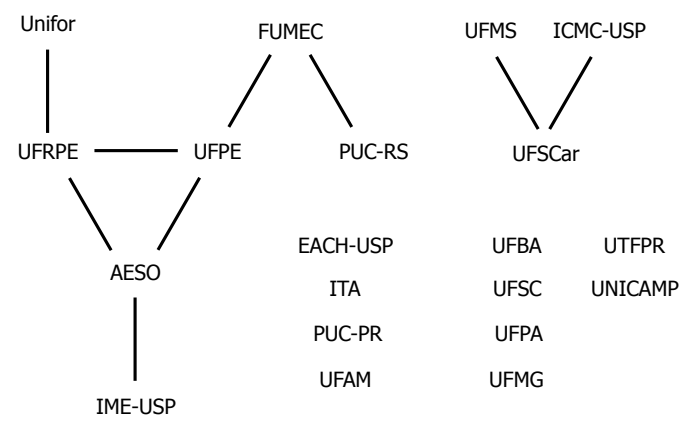

Fig. 2. Network of collaboration among researchers.

the conferences WBMA, ESELAW, WDRA and SBES ${ }^{13}$. We found 34 Brazilian scientific publications on Agile Software Development published between 2003 and 2010.

Figure 3 illustrates the trend in publications between 2003 and 2010. The studies fell into three thematic groups: introduction and adoption, use of tools and practices, and perceptions of agile methods. Experiences from the usage of Agile Software Development can be identified mostly in commercial settings. Although these studies and reports provides necessary insight into the possibilities and restrictions of Agile Software Development, concrete data is more difficult to find.

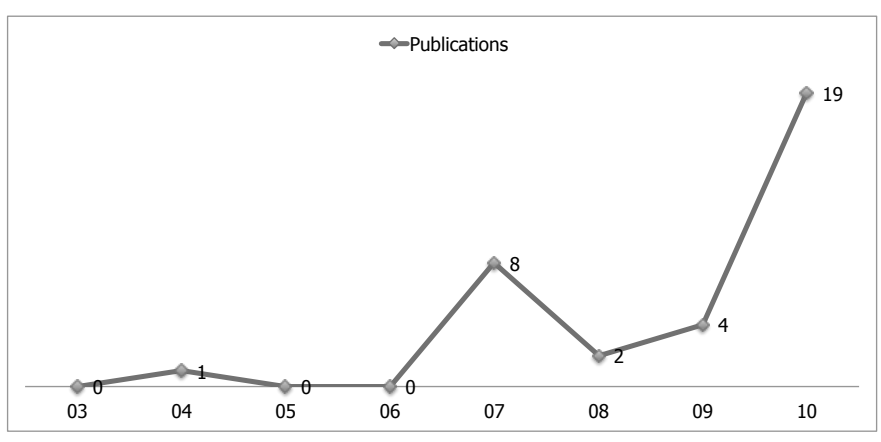

Fig. 3. Publications on Agile Software Development in the WBMA, ESELAW, WDRA and SBES.

The number of Brazilian authors and the number of Brazilian publications in the international scientific literature have grown substantially during the last four years. Figure 4 illustrates the trend in international publications between 2003 and 2010. Prior to 2003, no publication was found. Table II gives an overview of the studies according to publication venue. We see that the conferences International Conference on Agile Software Development (XP), Conferência Latinoamericana de Informática and ESELAW have the largest number of papers. Most works (40 of 46, 87\%) were published in conferences, while six (13\%) appeared in scientific journals.

\footnotetext{
${ }^{13}$ Simpósio Brasileiro de Engenharia de Software - http://www.each.usp.br/ cbsoft2011/portugues/sbes/sbes_pt.html
} 


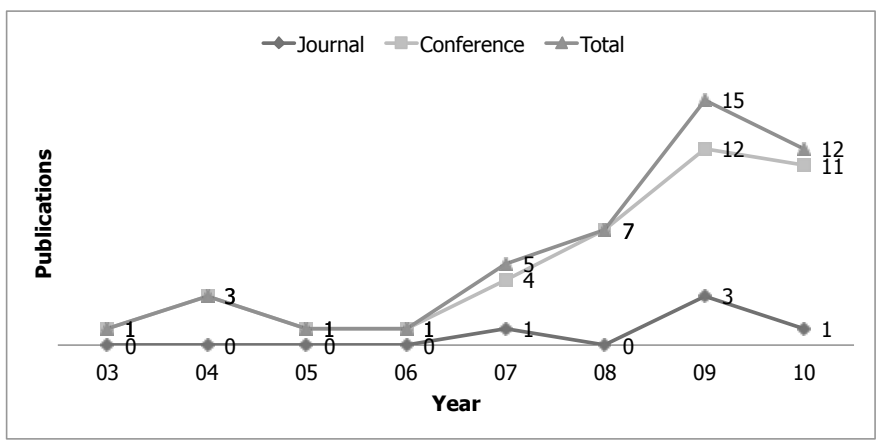

Fig. 4. Brazilian publications in international journals and conferences.

TABLE II

DISTRIBUTION OF BRAZILIAN PUBLICATIONS AFTER PUBLICATION VENUE AND OCCURRENCE.

\begin{tabular}{|c|c|c|}
\hline Publication Channel & Type & Percent \\
\hline $\begin{array}{l}\text { International Conference on Agile Software Development } \\
\text { (XP 20XX) }\end{array}$ & Conference & $19.6 \%$ \\
\hline Conferência Latinoamericana de Informática & Conference & $8.7 \%$ \\
\hline ESELAW & Conference & $8.7 \%$ \\
\hline Agile Development Conference & Conference & $2.2 \%$ \\
\hline Agiles & Conference & $6.5 \%$ \\
\hline $\begin{array}{l}\text { Conferencia IberoAmericana de Ingeniería de Requisitos } \\
\text { y Ambientes de Software }\end{array}$ & Conference & $6.5 \%$ \\
\hline Innovations in Systems and Software Engineering & Journal & $4.3 \%$ \\
\hline International Conference on Agile Manufacturing & Conference & $4.3 \%$ \\
\hline $\begin{array}{l}\text { International Conference on Software Engineering } \\
\text { Advances }\end{array}$ & Conference & $4.3 \%$ \\
\hline International Workshop On Web Quality & Conference & $4.3 \%$ \\
\hline Journal of Systems and Software & Journal & $4.3 \%$ \\
\hline $\begin{array}{l}\text { European Conference on Computer Supported } \\
\text { Cooperative Work }\end{array}$ & Conference & $2.2 \%$ \\
\hline $\begin{array}{l}\text { IEEE International Conference on Global Software } \\
\text { Engineering }\end{array}$ & Conference & $2.2 \%$ \\
\hline Information Resources Management Association & Conference & $2.2 \%$ \\
\hline International Conference Information Systems & Conference & $2.2 \%$ \\
\hline $\begin{array}{l}\text { International conference on quality of information and } \\
\text { communications technology }\end{array}$ & Conference & $2.2 \%$ \\
\hline International Conference on Software Testing & Conference & $2.2 \%$ \\
\hline $\begin{array}{l}\text { International Journal of Advanced Manufacturing } \\
\text { Systems }\end{array}$ & Journal & $2.2 \%$ \\
\hline Journal of Software Maintenance and Evolution & Journal & $2.2 \%$ \\
\hline $\begin{array}{l}\text { Portland Internaional Center for Management of } \\
\text { Engineering and Technology }\end{array}$ & Conference & $2.2 \%$ \\
\hline $\begin{array}{l}\text { Simpósio Internacional de Melhoria de Processo de } \\
\text { Software e de Sistemas }\end{array}$ & Conference & $2.2 \%$ \\
\hline Software and Systems Quality Confernece & Conference & $2.2 \%$ \\
\hline Software Engineering Process Group Latin America & Conference & $2.2 \%$ \\
\hline
\end{tabular}

\section{Agile Methods in the Industry}

Despite the fact that agile methods have been increasingly adopted and have "rapidly joined the mainstream of development approaches" [WG10], their adoption in the Brazilian IT industry has not been studied much in the literature. We aim to investigate the inception, growth and establishment of agile methods in this community. For this purpose, we conducted a survey of agile methods adoption in Brazil in 2011 and interviews with two acknowledged practitioners, considered Brazilian agile authorities.

\section{A. Research method}

We created a web-based survey ${ }^{14}$ consisting of 19 questions, most of which were based on a previous global survey on agile methods conducted by VersionOne [Ver10]. The main goal was to take an initial step towards understanding the Agile methods state-of-practice in the Brazilian IT industry. In addition, we designed a semi-structured interview (Appendix A) to gather further qualitative data from specialists of the Agile movement in Brazil.

When conducting research based on survey, probabilistic sampling of participants allows making inferences about population characteristics based on sample data. However, achieving a random sample of Internet users is problematic, if not impossible [SJ06]. Thus, we used non-probability sampling techniques, recommended for exploratory research [SR07]. We combined non-probability sample techniques, such as convenience and snowball methods to draw out our survey participants. For instance, convenience methods recruit respondents from online communities and discussion forums. Snowball sampling is based on the practice of asking participants to refer someone else to the survey, and so on. We drew out our survey participants from several databases, such as mailing lists, attendees of past Agile conferences, and Agilcoop ${ }^{15}$ business contacts. We sent them an email invitation to participate in the survey, and also invited their business contacts. We began the survey data collection in May, 2011 and the data analysed corresponds to 2 weeks of collection. In this period, we had 310 completed responses. As the survey will be completed by August, 2011, our results are preliminary.

The interview protocol was constructed from the authors expertise on the topic in order to develop an understanding of the phenomenon in study. We invited two Brazilian agile specialists, Klaus Wuestefeld and Vinícius Teles, and sent them an e-mail containing the interview questions. One of the interviewees answered by video, which allowed for more improvised answers. In this case, we transcribed the interview. We analysed the data by classifying interesting expressions and quotations related to the survey results.

\section{B. Results}

First, we depict the survey participants to date through respondent and company demographics. After that, we explore Brazilian interest in adopting agile methods, its growth and establishment in this community, and finally future expectations and challenges.

1) Participant characteristics: To characterize the participants in the survey, we illustrate their role, experience and exposure to Agile development in the next three graphs. Figure 5 exhibits an expressive quantity of roles related to developers, senior developers and project managers. In the option "Other", many of them could be grouped at team leader, systems analyst, tester, development manager, CIO/CTO, researcher and consultant/trainer roles.

\footnotetext{
${ }^{14}$ https://www.surveymonkey.com/s/KX93PGZ

${ }^{15}$ Cooperative for Agile Software Development composed of teachers, students and alumni of IME-USP
} 


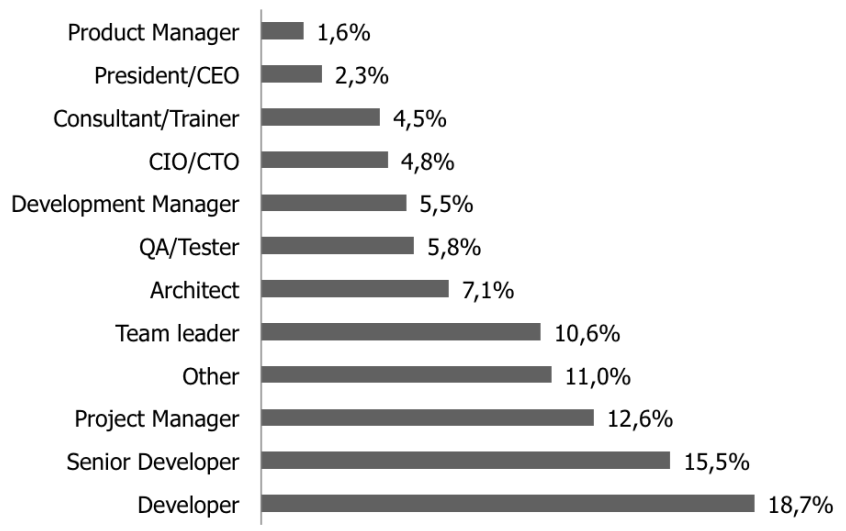

Fig. 5. Which role below best describes your current position in your company?

The participants' experience in practicing Agile development methods is outlined in Figure 6, consisting mostly of about between one and two years, and then between two and five years.

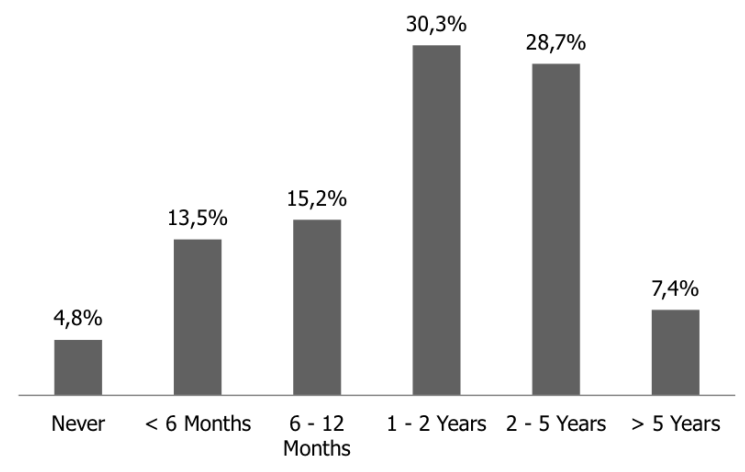

Fig. 6. How long have you personally been practicing Agile development methods?

Figure 7 depicts their current level of exposure to Agile development. It mainly relates to working as a member or leader of an agile team.

Also, we characterized the participants' organizations. The typical Brazilian software organization size, exposed in Figure 8 , consist of about 38 percent small organizations, about 16 percent very small organizations and 14 percent both mediumsized organizations and very large organizations.

Figures 9 frames participants' organizations main activity. Most of them are related to government and Internet, however in the option "Other", many of them were associated to software factory, information technology (IT) and research and development $(\mathrm{R} \& \mathrm{D})$ segments.

Figure 10 presents participants' organizations location. São Paulo and Distrito Federal refer to the majority respondents locations. As the results are preliminary, it is worth noting that we still cannot make any inference about the topic.

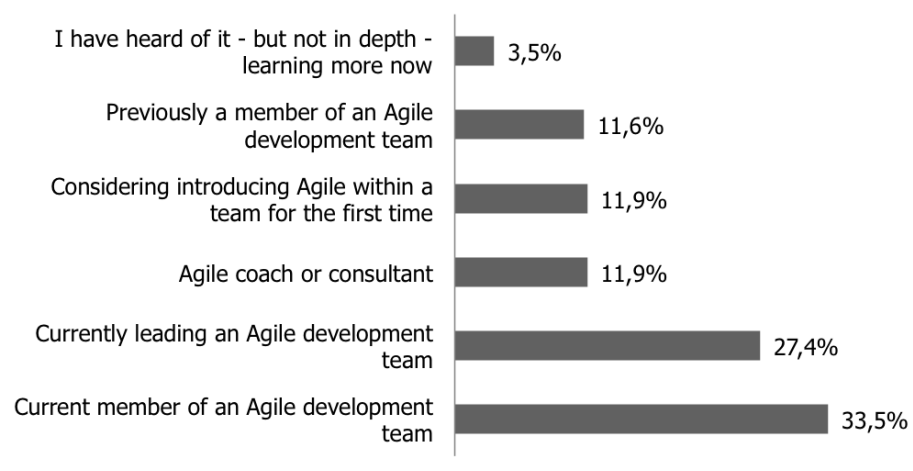

Fig. 7. What situation below best describes your current level of exposure to Agile development?

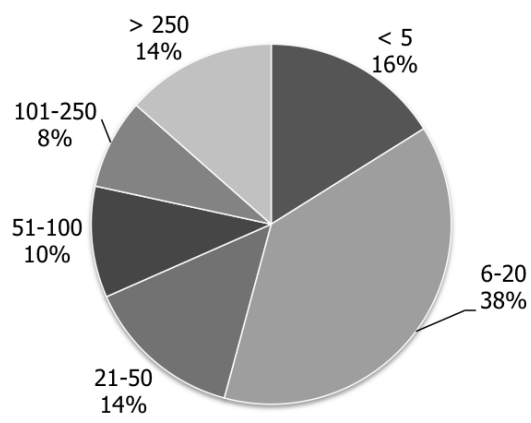

Fig. 8. How large is your total software organization?

Although we know that Rio de Janeiro and Minas Gerais are representative states in the Brazilian IT scenario, until the preliminary cut-off point, both of them have not participated effectively in the survey.

2) Brazilian interest in adopting agile methods: The global wave of dissatisfaction on software development also stimulated many Brazilian practitioners in searching an alternative approach that could increase the chances of software success. Figure 11 sums up the reasons participants found relevant for adopting Agile development methods.

In 1999, Klaus Wuestefeld got in contact with eXtreme Programming (XP) through links sent by his company colleague. He said that the XP ideas really captivated him. Then, in 2000, he decided to attend the first International Conference on XP. As he states that "It was an eye-opening experience".

An important issue raised by Vinícius Teles, was that, by the year of 2002, he was interested in understanding what could actually make a better project. The interviewee argued that "One thing that I realized was that human issues usually influenced the failure of a project".

Likewise, it was clear for both that people-oriented approaches should be considered to deal with important human issues, such as creativity, social skills and communication. In this manner, both undertake agile methods in their companies and contribute to spread the agile way of thinking through coaching/mentoring, training, lectures and publications (book 


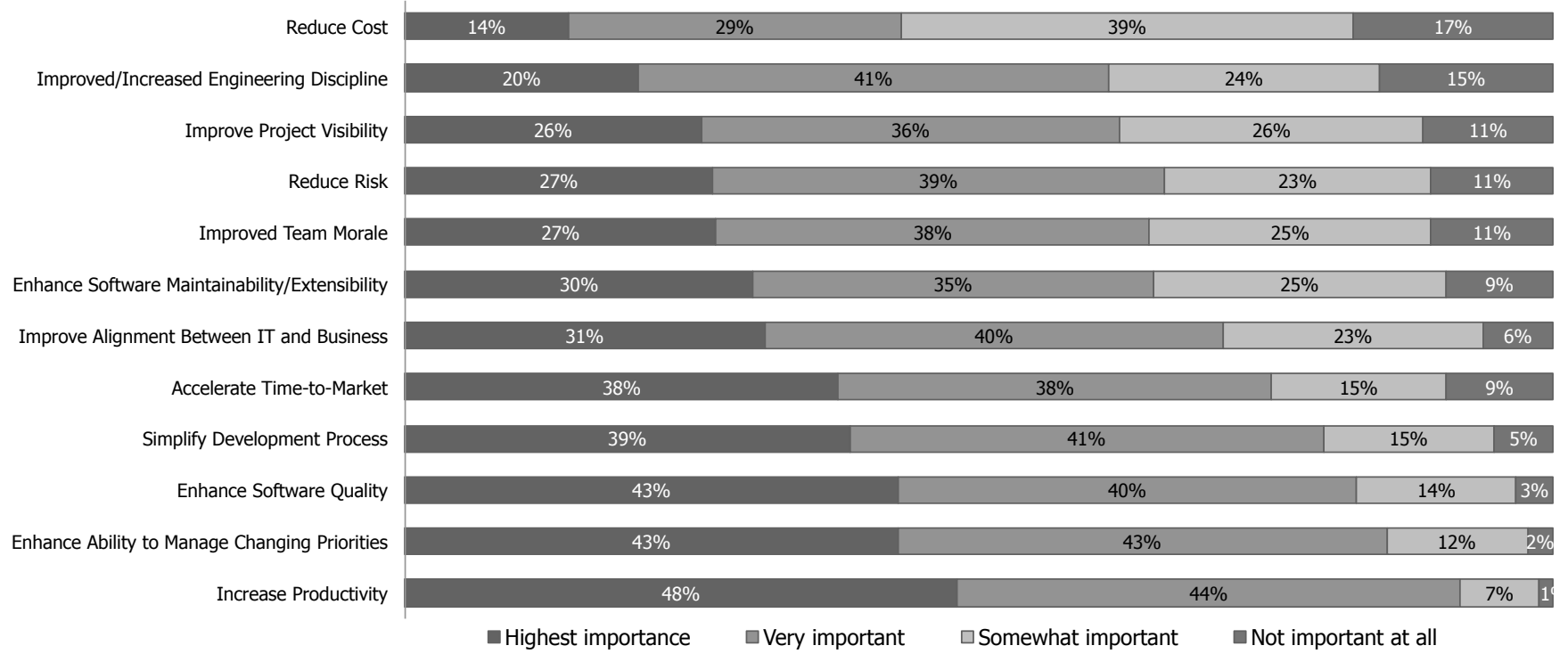

Fig. 11. What were the reasons for adopting Agile within your team or organization?

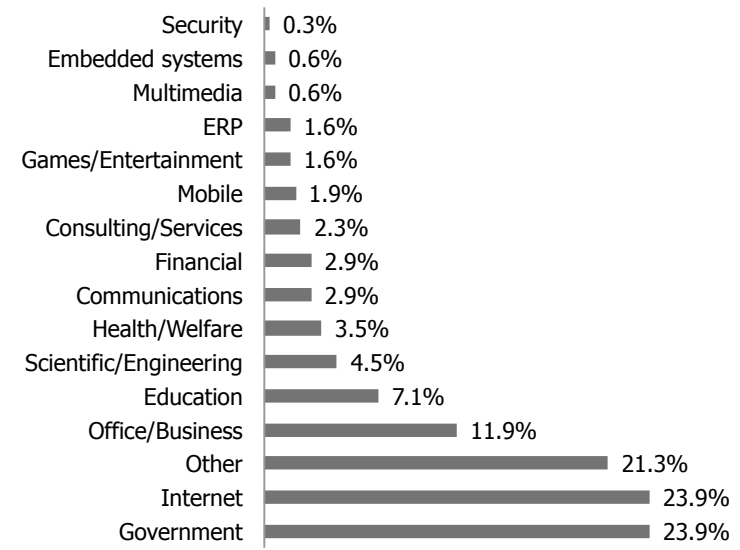

Fig. 9. What is the main activity of your organization?

and articles in websites/blogs) about agile methods.

3) Growth and establishment of the agile community in Brazil: For both interviewees, the growth of Brazilian agile community occurred through two main segments.

After the publication of the Agile Manifesto, the Brazilian agile adoption was fairly reticent, few of the beginners were quite seriously using it. Vinícius Teles argued that "There were not so many people interested in XP" and Klaus Wuestefeld added that "Agility started of as a subversive, grass-roots movement with XP and voluntary evangelists".

From 2006 on, as stated by Vinícius Teles "The growing was kind of explosive and now this became fashionable". Much of this was assigned to the arise of the Scrum method. Klaus Wuestefeld said that "With the advent of Scrum and its sex-appeal at management level, we started seeing agile methods brought in as a top-down approach, with professional

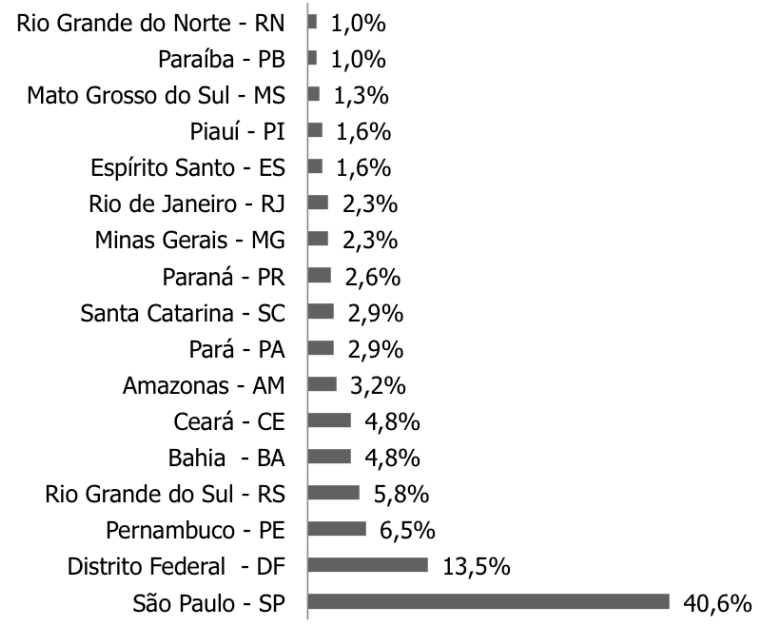

Fig. 10. Where your company is located?

consultants and Kafkian certification processes". About the Certified Scrum Master (CSM) courses, Vinícius Teles believes that "This creates so many dysfunctional behaviors in our community". However, even being very critical on certification processes, those initiatives drawn attention to a large number of organizations than the previous years.

In the past five years, agile methods have became much more popular to a wide range of organizations and practitioners in Brazil. Summarizing in words, much of this growth was due to the increase of the agile community through Scrum addressing agile management, certification courses, agile methods trainings, Brazilian agile conferences (e.g., Agile Brazil, WBMA, WDRA, "Encontro Ágil", etc.) and coaching/mentoring. 
Figure 12 outlines organizations' experience in practicing Agile development methods, which consists mostly of about between one and two years, and then between three and five years.

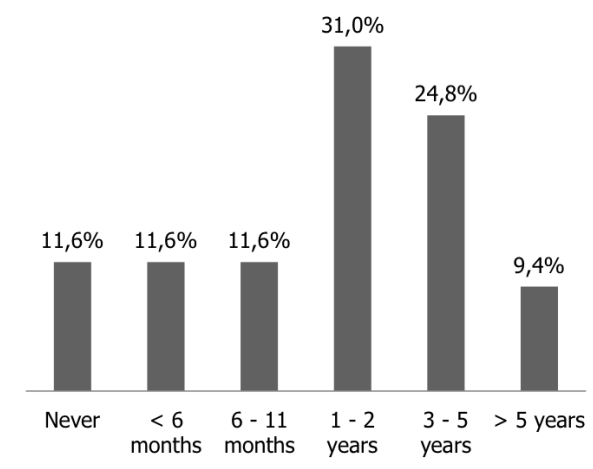

Fig. 12. How long has your company been practicing Agile development methods?

To endorse the expressive power of Scrum, Figure 13 shows that it is considered the agile method most followed in Brazil, succeeded by the combination of Scrum and XP, which is corroborated by Klaus Wuestefeld with the statement "In order to actually deliver something, Scrum teams have been adopting agile software engineering practices such as TDD/BDD, continuous integration and pair programming". In the option "Other", most respondents stated Test-Driven Development (TDD), FDD/Scrum Hybrid and the use of XP/Scrum with PMBOK.

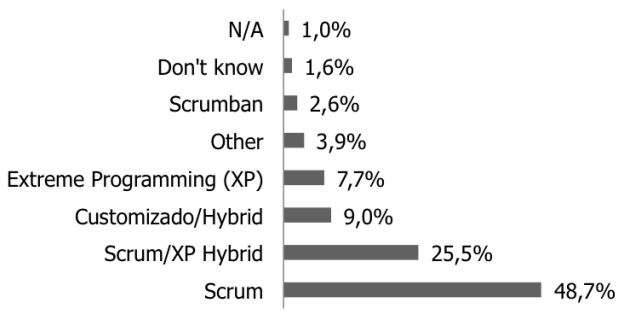

Fig. 13. Which Agile methodology do you follow most closely?

Figure 14 illustrates the percentage use of an agile method in organization's software projects. With the agile adoption, organizations may benefit in many ways, Figure 15 discloses the perceived benefits obtained from implementing agile.

4) Expectations and challenges for the future: It is difficult and ambitious to speak for the future in this domain, but the referred agile champions made some predictions about the way Brazilian software development community are going to cope with agile methods in the near future.

As declared by Vinícius Teles "People are becoming more and more interested in agile in many ways. I believe that agile methods will spread and increase a lot in the next few years". Also, will be very hard to reject the agile way of thinking as

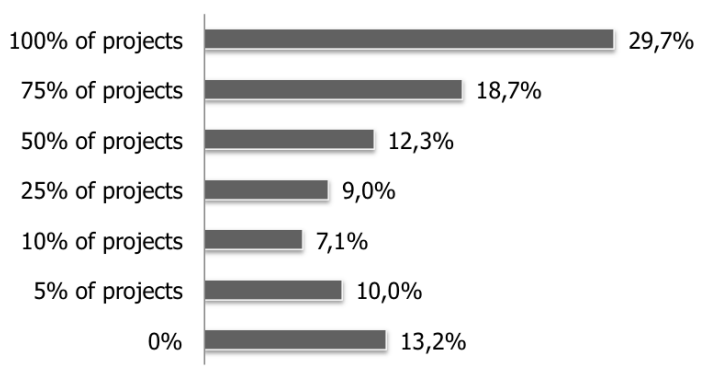

Fig. 14. What percent (\%) of your company's software projects use an Agile methodology?

stated by Klaus Wuestefeld "It is very difficult for anyone to defend a 'non-agile' position, whatever the case is".

At present days, the further agile adoption is harmed by barriers presented in Figure 16. In the option "Other", the main concerns were about adaptation to institutionalized processes in the organization (e.g., PMBOK, MPS.BR), lack of discipline and belief in agile methods, interpersonal issues and employee turnover.

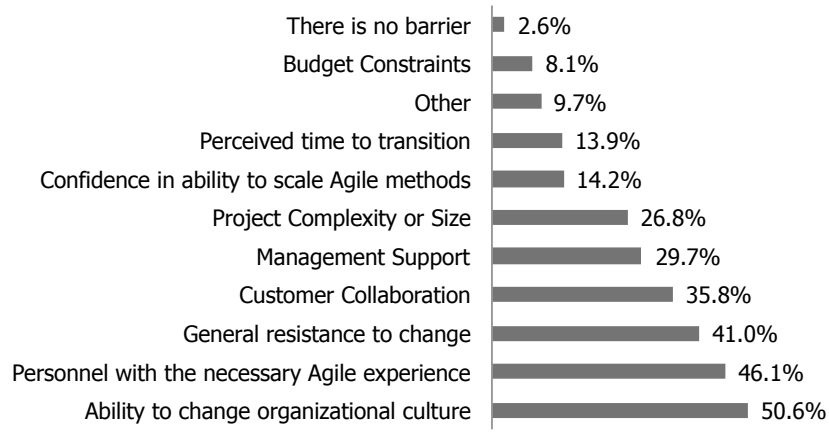

Fig. 16. What are the barriers to further adoption of Agile in your current organization?

The challenges Brazilian software organizations will have to face in this domain are also global challenges, as declared by Vinícius Teles.

Even agile being wide accepted in the industry, many practitioners have difficulties in embodying the whole agile values, principles and practices in their organizations. There are still dysfunctional behaviors in the way management thinks about how they should do software. Management still lacks the whole agile way of thinking and this is an important issue to consider when embodying agile.

Vinícius Teles said "To me, the challenge is in management. The management has to overcome their thinking, and shift to another one, which is, in a way, the opposite. I mean, the traditional way of management works in many kinds of companies, but it really doesn't work well at all, when we are talking about software development."

Klaus Wuestefeld also raised an important concern, "We brazilians still have to learn 'win-win'. We still see most 


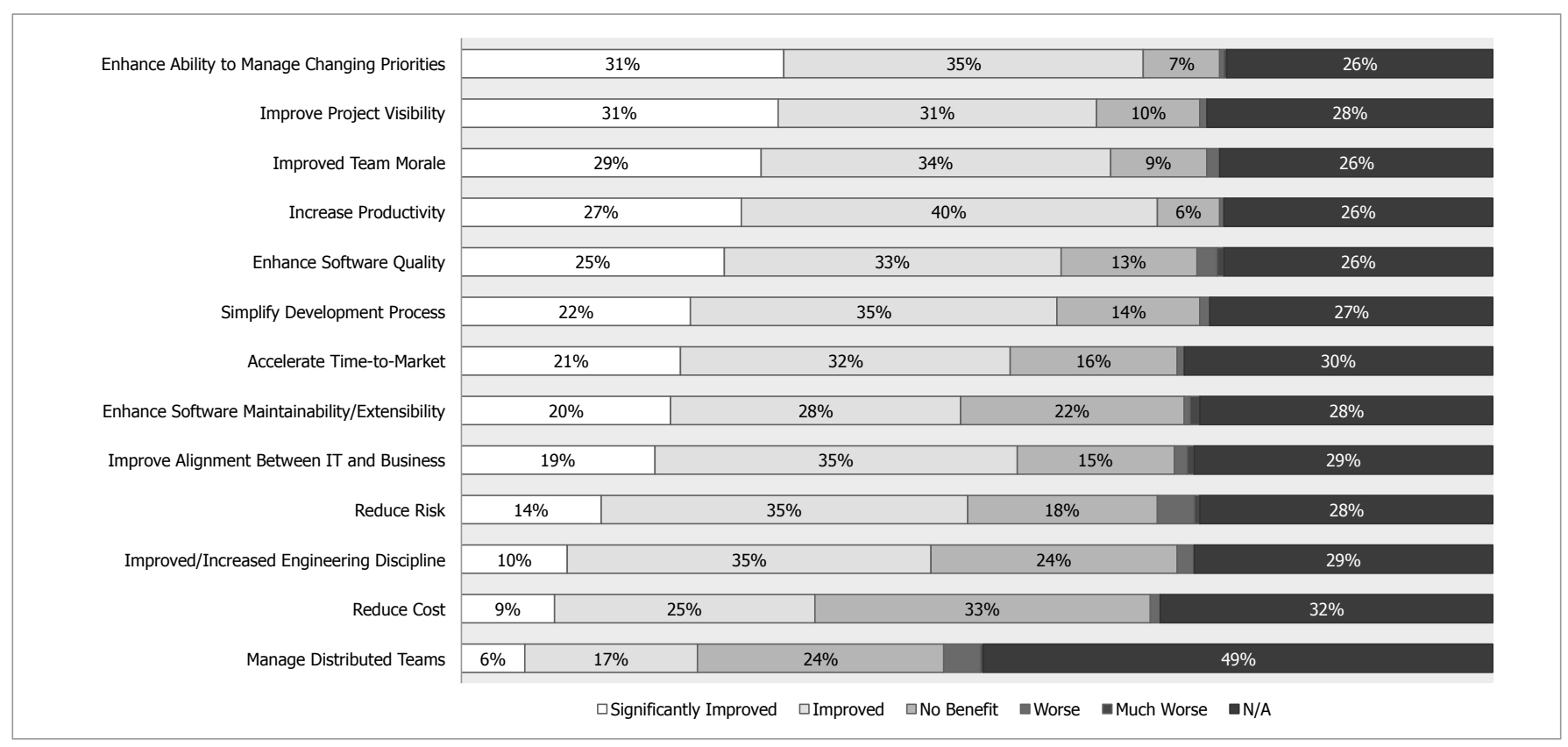

Fig. 15. What value have you actually realized from implementing Agile practices?

business deals as exploit opportunities for both sides rather than partnerships beneficial to all involved".

The challenges, stated by both interviewees, are mainly related to the shift of management thinking, the need for convincement at organization level, the type of agile adoption (full, gradual or partial) and the need for a suitable contract negotiation that involves trust and lacks fear.

\section{CONCLUSION}

In the early years of Agile Methods in Brazil, talks on the subject were received with great skepticism both by researchers in the academia and by software developers and managers in the industry. Often, a few members of the audience in a lecture about XP would become very aggressive with the ideas presented by the lecturer. Nowadays, this scenario changed completely. Most companies involved in software development claim that they follow at least some of the recommendations of the agile manifesto. Young developers are now educated with some contact with agile practices such as automated tests and continuous integration. Some even say that Agile Methods became mainstream.

Nevertheless, the culture and tradition of plan-based development and documentation-based evaluation of progress is still very strong in the Brazilian universities and companies. Thus, there is still a long way to go before Agile Methods be, in fact, pervasive in Brazil. Educators can help in that direction by modernizing university curricula, researchers can help by conducting experiments and evaluations of the quality and productivity of software developed with agile methods. However, as Thomas Kuhn states in The Structure of Scientific Revolutions [Kuh62], it might be necessary that a whole generation of managers and leaders get retired before the new paradigm of agile development become, in fact, widely used and mainstream.

\section{ACKNOWLEDGMENT}

We would like to thank all participants who contributed to the survey. This research is supported by FAPESP, Brazil, proc. 2009/10338-3, proc. 2009/16354-0, CNPq, Brazil, proc. $76661 / 2010-2$

\section{APPENDIX A}

Interview guide

- How was your first contact with agile methods?

- After this, to which companies (and/or projects) have you applied agile methods?

- Are you involved in some initiative of agile methods education (e.g., corporate training, undergraduate training, etc.)?

- Over the years, what have you noticed in regard to the growth and the establishment of the agile community in Brazil?

- What do you expect for the future of agile methods in Brazil?

- In your opinion, what challenges do Brazilian agile software organizations still have to overcome?

\section{REFERENCES}

[Bec99] K. Beck. Extreme Programming Explained: Embrace Change. 1999. Addison-Wesley, Reading, PA, 1999.

[BG10] M. Bravo and A. Goldman. Reinforcing the learning of agile practices using coding dojos. In Will Aalst, John Mylopoulos, Norman M. Sadeh, Michael J. Shaw, Clemens Szyperski, Alberto Sillitti, Angela Martin, Xiaofeng Wang, and Elizabeth Whitworth, editors, Agile Processes in Software Engineering and Extreme Programming, volume 48 of Lecture Notes in Business Information Processing, pages 379-380. Springer Berlin Heidelberg, 2010.

[Bro75] F. P. Brooks. The Mythical Man-Month: Essays on Software Engineering. Addison-Wesley, 1975.

[CB07] H. Corbucci and M. Bravo. Archimedes - o cad aberto: Uma aplicação para desenho técnico baseada na plataforma do eclipse. Workshop Software Livre, 2007. 
[GK11] A. Goldman and E. Katayama. Retrato da comunidade acadêmica de métodos Ágeis no brasil. Workshop Brasileiro de Métodos Ágeis (WBMA 2011), 2011.

[GKSY04] A. Goldman, F. Kon, P. J. S. Silva, and J. W. Yoder. Being extreme in the classroom: experiences teaching xp. Journal of the Brazilian Computer Society, 10(2):5-21, 2004.

[Kuh62] T. S. Kuhn. The Structure of Scientific Revolutions. University of Chicago Press, 1962.

$\left[\mathrm{MSM}^{+} 10\right]$ P. Meirelles, C. Santos, J. Miranda, F. Kon, A. Terceiro, and C. Chavez. A study of the relationships between source code metrics and attractiveness in free software projects. In 2010 Brazilian Symposium on Software Engineering (SBES), pages 11-20. IEEE, 2010.

[NJ82] J. D. Naumann and A. M. Jenkins. Prototyping: the new paradigm for systems development. MIS Quarterly, pages 29-44, 1982.

[OG11] R. M. Oliveira and A. Goldman. How to build an informative workspace? an experience using data collection and feedback. Agile 2011 Conference, 2011.

$\left[\mathrm{SAK}^{+} 04\right]$ A. F. Silva, C. Asmussen, F. Kon, A. Goldman, and C. E. Ferreira. Mico - university schedule planner. 5th Workshop on Free Software (WSL'2004), pages 147-150, 2004.

[SB01] Ken Schwaber and Mike Beedle. Agile Software Development with Scrum. Prentice Hall PTR, Upper Saddle River, NJ, USA, 1st edition, 2001.

[SGSF11] V. Santos, A. Goldman, A. C. M. Shinoda, and A. L. Fischer. A view towards organizational learning: An empirical study on scrum implementation. Software Engineering Knowledge Engineering, 2011.

[SJ06] M. Van. Selm and N. Jankowski. Conducting online surveys. Quality \& Quantity, 40:435-456, 2006.

[SR07] V. M. Sue and L. A. Ritter. Conducting Online Surveys. Sage Publications, Inc, 2007.

$\left[\mathrm{TCM}^{+}{ }^{10]}\right.$ A. Terceiro, J. Costa, J. Miranda, P. Meirelles, L. R. Rios, L. Almeida, C. Chavez, and F. Kon. Analizo: an extensible multi-language source code analysis and visualization toolkit Brazilian Conference on Software: Theory and Practice (Tools Session), 2010.

[Ver10] VersionOne. 5th annual state of agile development. http://pm. versionone.com/StateOfAgileSurvey.html, 2010.

[WG10] D. West and T. Grant. Agile Development: Mainstream Adoption Has Changed Agility - Trends In Real-World Adoption Of Agile Methods. Technical report, Forrester Research, January 2010. 